\title{
Correction to: Thermal Field-Flow Fractionation as a Powerful Tool for the Fractionation of Complex Synthetic Polymers: A Perspective
}

\author{
Harald Pasch ${ }^{1}$
}

Published online: 31 May 2021

(c) Springer-Verlag GmbH Germany, part of Springer Nature 2021

\section{Correction to: Chromatographia (2021) 84: 525-530 https://doi.org/10.1007/s10337-021-04036-9}

In the Original publication, author biography was missed out. It is given below.

Publisher's Note Springer Nature remains neutral with regard to jurisdictional claims in published maps and institutional affiliations.

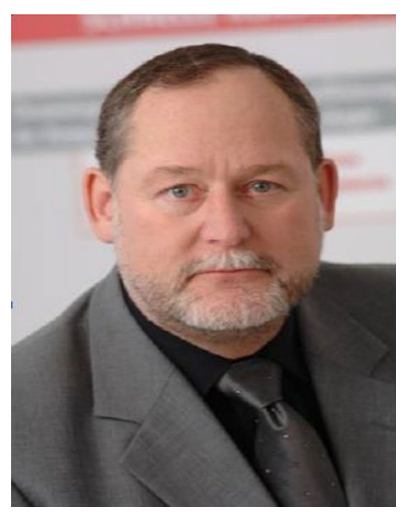

Harald Pasch is a Distinguished Professor at the Department of Chemistry and Polymer Science, University of Stellenbosch, South Africa. His research focuses on the development of advanced analytical methods for complex polymers. He is the author/co-author of more than 350 scientific papers and he promoted more than 60 postgraduate students (MSc and PhD). In 2013, he published the textbook 'Multidimensional HPLC of Polymers'. The textbook 'Advanced Separation Techniques for Polyolefins' appeared in 2014 and his latest textbook 'Thermal Field-Flow Fractionation of Polymers' was published in 2019.

The original article can be found online at https://doi.org/10.1007/ s10337-021-04036-9.

Harald Pasch

hpasch@sun.ac.za

1 Department of Chemistry and Polymer Science, University of Stellenbosch, Post Box X1, Stellenbosch 7602,

South Africa 